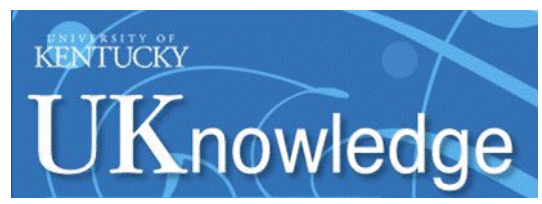

University of Kentucky

UKnowledge

2-21-2015

\title{
Horror Vacui: Emptiness Might Distinguish between Major Suicide Repeaters and Nonmajor Suicide Repeaters: A Pilot Study
}

\author{
Hilario Blasco-Fontecilla \\ Autonoma University, Spain \\ Enrique Baca-Garcia \\ CIBERSAM, Spain \\ Philippe Courtet \\ University of Montpellier, France \\ Rebeca Garcia Nieto \\ CIBERSAM, Spain \\ Jose de Leon \\ University of Kentucky, jdeleon@uky.edu
}

Follow this and additional works at: https://uknowledge.uky.edu/psychiatry_facpub

Part of the Psychiatry and Psychology Commons

Right click to open a feedback form in a new tab to let us know how this document benefits you.

\section{Repository Citation}

Blasco-Fontecilla, Hilario; Baca-Garcia, Enrique; Courtet, Philippe; Nieto, Rebeca Garcia; and de Leon, Jose, "Horror Vacui: Emptiness Might Distinguish between Major Suicide Repeaters and Nonmajor Suicide Repeaters: A Pilot Study" (2015). Psychiatry Faculty Publications. 31.

https://uknowledge.uky.edu/psychiatry_facpub/31

This Letter to the Editor is brought to you for free and open access by the Psychiatry at UKnowledge. It has been accepted for inclusion in Psychiatry Faculty Publications by an authorized administrator of UKnowledge. For more information, please contact UKnowledge@lsv.uky.edu. 
Horror Vacui: Emptiness Might Distinguish between Major Suicide Repeaters and Nonmajor Suicide Repeaters: A Pilot Study

Digital Object Identifier (DOI)

http://dx.doi.org/10.1159/000369937

Notes/Citation Information

Published in Psychotherapy and Psychosomatics, v. 84, no. 2, p. 117-119.

(C) 2015 S. Karger AG, Basel

The copyright holder has granted the permission for posting the article here.

The document available for download is the authors' post-peer-review final draft of the article. 
Number of words: 1018

Number of Tables: 1 Number of References: 10

\section{Research letter:}

Horror vacui*: Emptiness might distinguish between major suicide repeaters and nonmajor suicide repeaters. A pilot study.

Hilario Blasco-Fontecilla, ${ }^{1,2 *}$ Enrique Baca-Garcia, ${ }^{3}$ Philippe Courtet, ${ }^{4,5}$ Rebeca Garcia-Nieto, ${ }^{3}$ Jose de Leon ${ }^{6}$

${ }^{1}$ Department of Psychiatry, Puerta de Hierro University Hospital, IDIPHIM, CIBERSAM, Autonoma University, Madrid, Spain

${ }^{2}$ Consulting Asistencial Sociosanitario (CAS), Madrid, Spain

${ }^{3}$ Department of Psychiatry, IIS-Jimenez Diaz Foundation, CIBERSAM, Madrid, Spain, where the study was conducted.

${ }^{4}$ Department of Emergency Psychiatry and Post Acute Care, CHU Montpellier, University of Montpellier, France

${ }^{5}$ Fondamental Foundation, France

${ }^{6}$ Mental Health Research Center at Eastern State Hospital, Lexington, KY, USA

*Corresponding author: Hilario Blasco-Fontecilla, Department of Psychiatry, Puerta de Hierro University Hospital, IDIPHIM, Calle Manuel de Falla, 1, 28222 Majadahonda, Madrid, Spain. email: hmblasco@yahoo.es hblasco@idiphim.org Phone 34-911 916000, Fax +34-918514707 Running head: major suicide repeaters and emptiness

\footnotetext{
${ }^{*}$ In visual art, this Latin expression means the filling of the entire surface of an artwork or space with detail
} 
Empty societies create empty people. No societies perhaps have ever been more empty than those that exist in our present time, on the frontiers of modernity.

http://www.theapricity.com/forum/showthread.php?4784-Empty-societies-create-empty-people Major repeaters (individuals with $\geq 5$ lifetime suicide attempts) account for $10 \%$ of all suicide attempters, and pose a challenge to clinicians [1]. Recently, we have proposed that major repeaters are a distinct phenotype within suicidal behaviors (SBs) and may share some common features with patients with addictions [2]. Moreover, major repeaters may attempt suicide for different reasons than suicide attempters less prone to repetition. Unfortunately, there is virtually no published information with regard to the functional processes (reasons) that produce and maintain SBs in major repeaters.

Nock \& Prinstein [3] proposed four primary functions of self-mutilating behavior that can also be applied to SBs [4]. The four functions differ along two dimensions: contingencies (automatic versus social), and reinforcement (positive versus negative). In automatic-negative reinforcement (ANR), individuals engage in SBs to achieve a reduction of negative affective states (e.g., "to stop bad feelings"). Automatic-positive reinforcement (APR) refers to an individual's using SBs to create a desirable physiological state (e.g., "to feel something, because you felt numb or empty"). Social-negative reinforcement (SNR) refers to an individual using SBs to escape from interpersonal task demands (e.g., "to avoid punishment"), and social-positive reinforcement (SPR) refers to using SBs for gaining attention from others (e.g., "to let others know how unhappy I am").

The major aim of this study is to explore these four functions of suicide attempts in major repeaters. Details on the procedures of this study have been reported elsewhere [5]. Basically, 82 individuals who had attempted suicide at least once during their lifetime were recruited from a 
Psychiatric Short-Stay Unit in 2012. All participants were administered the Spanish version of the Self-Injurious Thoughts and Behaviors Interview (SITBI) [5]. Characteristics of suicide attempts included reported function using a Likert scale (0 to 4$)$ and referred to the most lethal suicide attempt recalled by the participant, as stated in the SITBI. Significant variables $(p<0.05)$ in univariate analyses were introduced in multivariate logistic regression models (Table 1).

Most of the 82 individuals were Caucasian, single, and had high school educations. 49\% were women. The mean (SD) age was 43.3 years (10.3). Among these 82 individuals there were 11 (13\%) major repeaters ( $\geq 5$ attempts) [2] and 71 (87\%) non-major repeaters respectively, including $35(42 \%)$ with a single attempt and $36(45 \%)$ with 2 to 4 lifetime suicide attempts. The univariate analyses of clinical variables indicated that there were no significant differences in clinical variables between repeaters and non-major repeaters with the exception of borderline personality disorder (BPD) (45\% vs. $14 \%$; FET $\mathrm{p}=0.027$; OR was $5.0 ; 95 \% \mathrm{CI}=1.3,19.5)$. All major repeaters and $93 \%$ of the remaining suicide attempters had at least one Axis I diagnosis. Major repeaters were statistically more likely to report $A P R$ than non-major repeaters (OR 4.9; $95 \%$ CI 1.3, 18.3). ANR, SNR, and SPR were not significantly more frequent in major repeaters (Table 1). A logistic regression model with major attempter as the dependent variable verified that the association between major repeater status and $A P R$ was not completely explained by the association between major attempter status and BPD (see Table 1, footnote ${ }^{2}$ and footnote ${ }^{4}$.

The present pilot study confirms that ANR ("To stop bad feelings, psychological pain") is reported most frequently as the reason for SB. In our sample these reports were present in almost all attempters ( $86 \%$ of non-major repeaters and $91 \%$ of major repeaters). This finding supports the concept that people may attempt suicide to relieve a painful or unbearable internal state [6], and places psychological pain at the core of SB [7]. Shneidman [7] and, more recently, Tossani 
[8] stressed the strong link between psychological pain and SB. However, ANR did not differentiate between major and non-major repeaters in our pilot study.

On the other hand, major repeaters were nearly 5 times more likely than non-major repeaters to endorse $A P R$ ("To feel something, because you felt numb or empty") as a reason for attempting suicide. SBs may also function as a means of generating feelings. Emptiness, which is one of the factors of the Orbach \& Mikulincer Mental Pain questionnaire [6], is considered a relevant factor influencing the occurrence of $\operatorname{SBs}[9,10]$. This study extends our previous findings by suggesting that emptiness appears to be particularly relevant as a reason for SB for major repeaters. Although speculative, it is possible that major repeaters were more likely victimized during childhood or adolescence. In a previous work, we found that major repeaters were more likely to be diagnosed with any type of childhood maltreatment, and childhood and adolescent victimization have been related to the repetition of SB [2].

Finally, the relationship between $A P R$ and major repeater status was more relevant than the relationship between BPD and major repeater status. In other words, individuals who attempt suicide because they feel empty or numb, or just want to feel something, even if pain, were more likely to be major repeaters. This occurs in patients with BPD and in other patients. We acknowledge that there are probably other pathways leading to major repetition of SBs, but our pilot study strongly suggests that one of the major ones may be relieving emptiness.

Future studies should consider some of the limitations of the present study. As in all retrospective studies, the current study provided statistical associations that cannot be interpreted as providing etiological links. As explained elsewhere [2], we collapsed single attempters and "minor repeaters" into one category to gain statistical power [2]. Furthermore, we "equated" $A P R$ to emptiness in our discussion, and the concept of $A P R$ as a motivation for suicide attempts 
may have served to elicit other sensations such as pain or satisfaction. In any case, the different sensations usually included in APR tend to load onto the same factor [3].

In conclusion, the primary purpose of most suicide attempts is the regulation of emotions. $A P R$ and $A N R$ are frequent among major repeaters, but only $A P R$ significantly distinguished major repeaters from non-major repeaters. Therapeutic approaches focused on enhancing emotion regulation would be most effective [3].

\section{Acknowledgments}

The authors thank Lorraine Maw, M.A., for editorial assistance.

\section{Disclosure statements}

This article received no support from any funding agency, commercial business, or notfor-profit institution. In the last three years, Dr. Hilario Blasco-Fontecilla has received lecture fees from Eli Lilly, AB-Biotics, Janssen, and Shire. In the last 3 years, Dr. Philippe Courtet received research grants from Janssen, Otsuka, Servier and honoraria for presentations in congresses from AstraZeneca, Bristol-Myers Squibb, Janssen, Lundbeck, Otsuka, Pfizer and Servier. The remaining authors declare no commercial conflicts of interest in the last 3 years. 


\section{References}

1 Kreitman N, Casey P: Repetition of parasuicide: An epidemiological and clinical study. Br J Psychiatry 1988;153:792-800.

2 Blasco-Fontecilla H, Jaussent, I., Olié, E., Béziat, S. Guillaume, S., Artieda-Urrutia, P., Baca-Garcia, E., de Leon, J., Courtet, P.: Major repeaters: A distinct phenotype of suicidal behavior? Prim Care Companion CNS Disord 2014;16 doi:10.4088/PCC.14m01633

3 Nock MK, Prinstein MJ: A functional approach to the assessment of self-mutilative behavior. J Consult Clin Psychol 2004;72:885-890.

$4 \quad$ Nock MK: Why do people hurt themselves? New insights into the nature and functions of self-injury. Curr Dir Psychol Sci 2009;18:78-83.

5 Garcia-Nieto R, Blasco-Fontecilla, H., de Leon-Martinez, V., Baca-Garcia, E.: Clinical features associated with suicide attempts vs suicide gestures in an inpatient sample. Arch Suicide Res 2014; doi: 10.1080/13811118.2013.845122

6 Orbach I, Mikulincer M, Gilboa-Schechtman E, Sirota P: Mental pain and its relationship to suicidality and life meaning. Suicide Life Threat Behav 2003;33:231-241.

$7 \quad$ Shneidman ES: Suicide as psychache. J Nerv Ment Dis 1993;181:145-147.

8 Tossani E: The concept of mental pain. Psychother Psychosom 2013;82:67-73.

9 Blasco-Fontecilla H, Delgado-Gomez D, Ruiz-Hernandez D, Aguado D, Baca-Garcia E, Lopez-Castroman J: Combining scales to assess suicide risk. J Psychiatr Res 2012;46:12721277.

10 Blasco-Fontecilla H, de Leon-Martinez, V., Delgado-Gomez, D., Giner, L., Guillaume, S., Courtet, P.: Emptiness and suicidal behavior: An exploratory review. Suicidology Online $2013 ; 4: 21-32$. 
Table 1. Univariate and backward stepwise logistic regression model for major repeaters.

\begin{tabular}{|c|c|c|c|c|c|c|}
\hline \multicolumn{7}{|c|}{ UNIVARIATE ANALYSES } \\
\hline & $\begin{array}{c}\text { Major } \\
\text { repeater } \\
(n=11) \%\end{array}$ & $\begin{array}{c}\text { Non- } \\
\text { major } \\
\text { repeater } \\
(\mathrm{n}=71) \%\end{array}$ & \multicolumn{2}{|c|}{ FET p-value } & $\begin{array}{l}\text { Univariate } \\
\text { OR }\end{array}$ & $95 \% \mathrm{CI}$ \\
\hline \multicolumn{7}{|l|}{ Reported function $^{1}$} \\
\hline $\begin{array}{l}\text { Automatic negative } \\
\text { reinforcement }\end{array}$ & 91 & 86 & \multicolumn{2}{|c|}{1.0} & 1.6 & $0.19-14.2$ \\
\hline $\begin{array}{l}\text { Automatic } \\
\text { reinforcement }\end{array}$ & 55 & 20 & \multicolumn{2}{|c|}{0.021} & $4.9^{2}$ & $1.3-18.3$ \\
\hline $\begin{array}{l}\text { Social } \\
\text { reinforcement }\end{array}$ & 0 & 24 & \multicolumn{2}{|c|}{0.11} & 3 & \\
\hline \multirow[t]{3}{*}{$\begin{array}{l}\text { Social } \\
\text { reinforcement }\end{array}$} & 18 & 42 & \multicolumn{2}{|c|}{0.19} & 0.30 & $0.06-1.5$ \\
\hline & \multicolumn{6}{|c|}{ BACKWARD STEPWISE LOGISTIC REGRESSION MODEL ${ }^{4}$} \\
\hline & \multicolumn{2}{|c|}{ Variable } & ${ }^{5}$ Wald $\chi^{2}$ & p values & $\begin{array}{c}\text { Corrected } \\
\text { OR } \\
\end{array}$ & $95 \% \mathrm{CI}$ \\
\hline \multirow[t]{2}{*}{ First step } & \multicolumn{2}{|c|}{$\begin{array}{l}\text { Automatic positive } \\
\text { reinforcement }\end{array}$} & 2.5 & 0.11 & 3.2 & $0.76-13.9$ \\
\hline & \multicolumn{2}{|c|}{$\begin{array}{l}\text { Borderline personality } \\
\text { disorder }\end{array}$} & 2.2 & 0.14 & 3.1 & $0.70-14.1$ \\
\hline Second step & \multicolumn{2}{|c|}{$\begin{array}{l}\text { Automatic positive } \\
\text { reinforcement }\end{array}$} & 5.5 & 0.019 & 4.9 & $1.3-18.3$ \\
\hline
\end{tabular}

CI: confidence interval. FET: Fisher exact test; OR: odd ratio. Significant results are in italics.

Automatic negative reinforcement: "To stop bad feelings". Automatic positive reinforcement: "To feel something, because you felt numb or empty". Social negative reinforcement: "To avoid doing something you don't want to do". Social positive reinforcement: "To communicate with someone or get his/her attention".

${ }^{1}$ Patients presenting high levels: (2-4 vs. 0-1) in the Spanish version of the Self-Injurious Thoughts and Behaviors Interview (SITBI).

${ }^{2}$ This univariate OR is not adjusted by the association between automatic positive reinforcement and borderline personality disorder. These two variables were significantly associated (FET $\mathrm{p}=0.001 ; \mathrm{OR}=7.6, \mathrm{CI} 2.3,25.8$ ).

${ }^{3}$ One of the cells has a 0 value. Therefore, it is not possible to calculate an OR.

${ }^{4}$ Further statistical proof of the greater importance of automatic positive reinforcement in predicting major attempter status was done with a logistic regression model using the interaction between automatic positive reinforcement and borderline personality disorder as an additional variable. This interacting variable can be thought as representing the overlap of these two variables. When automatic positive reinforcement, borderline personality disorder, and the interacting 
variable were introduced in the backward stepwise logistic regression models with major attempter status as the dependent variable, it was interesting that automatic positive reinforcement was the only variable selected by the model as significant. This can be interpreted to mean that the significant association between major repeater status and automatic positive reinforcement was not explained by personality disorder nor by the overlap between automatic positive reinforcement and borderline personality disorder. The logistic regression model included a constant not described in the table. The Hosmer-Lemeshow test was non-significant $(\chi 2=.042 ; \mathrm{df}=2 ; \mathrm{p}=0.98)$, suggesting that the model fit the data well.

${ }^{5}$ Degrees of freedom $=1$. 